\title{
Effectiveness of health education in the self-care and adherence of patients with heart failure: a meta-analysis
}

\footnotetext{
Juliana de Melo Vellozo Pereira Tinoco

(D) https://orcid.org/0000-0002-2418-6984

Lyvia da Silva Figueiredo $0^{2,3}$

(D) https://orcid.org/0000-0003-1591-422X

Paula Vanessa Peclat Flores ${ }^{4}$

(D) https://orcid.org/0000-0002-9726-5229

Bruna Lins Rocha de Padua ${ }^{1}$

(1Dhttps://orcid.org/0000-0002-9993-5337

Evandro Tinoco Mesquita ${ }^{4}$

(1Dhtps://orcid.org/0000-0002-7452-3870

Ana Carla Dantas Cavalcanti ${ }^{4}$

(1Dhttps://orcid.org/0000-0003-3531-4694
}

1 Universidade Federal Fluminense, Hospital Universitário Antônio Pedro, Niterói, RJ, Brazil.

2 Universidade Federal Fluminense, Niterói, RJ, Brazil.

${ }^{3}$ Scholarship holder at the Coordenação de Aperfeiçoamento de Pessoal de Nível Superior (CAPES), Brazil.

${ }^{4}$ Universidade Federal Fluminense, Escola de Enfermagem Aurora de Afonso Costa, Niterói, RJ, Brazil.

\begin{abstract}
Objective: to evaluate in the literature the effectiveness of the health education interventions in self-care and adherence to treatment of patients with Chronic Heart Failure. Method: a systematic review with meta-analysis. Studies were selected that compared health education interventions with the usual care to assess the outcomes of adherence and self-care. The quality of the methodological evidence was assessed by the Grading of Recommendations, Assessment, Development and Evaluation system. Results: the educational interventions were more effective in relation to the usual care in the outcome of adherence (fixed effect $=0-3841 ; p$-value $<0.001$ ). There was no statistical difference in the outcome of self-care (fixed effect $=0.0063 ; p$-value $=0.898)$. Conclusion: the educational interventions improved the outcome of adherence, though not self-care in the patient with Heart Failure.
\end{abstract}

Descriptors: Self Care; Heart Failure; Patient Complicance; Health Education; Health Outcome; Treatment Adherence and Compliance.

\section{How to cite this article}

Tinoco JMVP, Figueiredo LS, Flores PVP, Pádua BLR, Mesquita ET, Cavalcanti A. Effectiveness of health education in the selfcare and adherence of patients with heart failure: a meta-analysis. Rev. Latino-Am. Enfermagem. 2021;29:e3389. [Access f f f]; Available in: DOI: http://dx.doi.org/10.1590/1518-8345.4281.3389. 


\section{Introduction}

Heart Failure (HF) is a complex clinical syndrome, in which dyspnea, fatigue and fluid retention can limit tolerance to exercise and functional capacity ${ }^{(1)}$. Despite advances in pharmacological and non-pharmacological follow-up, HF affects thousands of people worldwide and is associated with frequent use of the health services ${ }^{(2)}$.

A number of studies point out that the prevalence of HF can affect nearly $1 \%-2 \%$ of the world population, with $6 \%$ to $10 \%$ of the individuals being over 65 years old $^{(3-4)}$. In Brazil, between June 2018 and June 2019, HF totaled 212,208 thousand cases of hospitalizations and 24,035 thousand deaths. These numbers point to $\mathrm{HF}$ as the leading cause of hospitalization for diseases of the circulatory system and the second leading cause of mortality in Brazil(5).

Lack of adherence to the therapeutic regimen, especially with regard to lifestyle changes, is one of the factors that contribute for decompensation episodes and readmission due to $\mathrm{HF}^{(1,6-7)}$. However, one of the main reasons for lack of adherence is the low capacity of the individuals to exercise their self-care ${ }^{(8-9)}$, which is understood as the natural decision-making process of individuals and their families, aimed at both the prevention and treatment of the disease ${ }^{(10-11)}$.

In HF, the capacity for self-care can be limited by low health literacy, cognitive deficit, depressive symptoms, presence of multiple comorbidities and low self-efficacy to perform self-care ${ }^{(12-14)}$

The low health literacy in patients with HF translates into less knowledge related to the disease, worse self-care behavior, low quality of life and decreased medication adherence prescribed in HF. It is also associated with the incidence of mortality in outpatients and inpatients. In addition, it is emphasized that low health education can predict morbidity and mortality ${ }^{(15-16)}$.

These factors directly affect patient adherence and interaction with health professionals, since it is a complex process that ranges from complying with and following the treatment prescribed in search for well-being and health, represented by changes in the lifestyle that include attending appointments and greater control of the medication ${ }^{(17)}$.

A number of studies indicate that, with an adequate guidance on the disease and patient involvement in selfcare, health outcomes improve ${ }^{(18-19)}$. Patient education is a fundamental component of $\mathrm{HF}$ care management programs, in addition to optimizing clinical treatment and psychosocial support. This strategy reduces hospitalization due to HF and mortality in post-discharge patients(20).
There are currently several educational interventions for patients with HF in order to improve self-care and adherence to the treatment. However, the researchers did not find in the literature any synthesis of evidence on educational interventions and the impact of these interventions on self-care and adherence, in order to generate recommendations for clinical decision-making in the professional practice. Similar articles were assessed in order to reduce subjectivity by standardizing measures of effect, in addition to making recommendations on which interventions are most effective for the outcomes proposed in this study.

This review can guide health professionals who work in clinics specialized in $\mathrm{HF}$, outpatient clinics or in the hospital environment when making decisions about the best educational intervention to achieve self-care and adherence with HF patients.

Thus, this study aimed to assess in the literature the effectiveness of the health education interventions in self-care and adherence to the treatment of patients with Chronic Heart Failure.

\section{Method}

This is a systematic review with meta-analysis, conducted according to the precepts of the Joanna Briggs Institute (JBI) - Evidence Synthesis Groups, in addition to the indications of the Preferred Reporting Items for Systematic Reviews and Meta-Analyses (PRISMA)(21).

The protocol entitled "The effectiveness of interventions in health education in the adherence to treatment and self-care of patients with heart failure: a systematic review" is published in the PROSPERO platform under number CRD42018094051.

The review had the following guiding question: What is the effectiveness of health education in the adherence to the treatment and self-care of patients with HF?

For the elaboration of the guiding question and search for articles, the PICO strategy was used, which is an acronym for Patient/Problem (heart failure), Intervention (health education), Control/Comparison and Outcomes (patient compliance, self-care)(22). It should be noted that, in the PICO strategy of this study, the " $C$ " was not inserted as a specific intervention, since any intervention deemed as control in the articles was considered for comparison analysis with health education interventions.

The following inclusion criteria were adopted: studies with adults over 18 years of age with $\mathrm{HF}_{\text {, addressing }}$ a health education intervention for adherence to the treatment and/or self-care; indexed in databases published in English, Spanish or Portuguese between 2012 and 2019, regardless of the professional area. The 
time cut is justified by the need to check health education interventions updated in light of the technological and health advances in recent decades.

This review considered studies with an experimental or quasi-experimental design, such as without randomization with a single group pre- and post-test, observational, including prospective and retrospective cohort, case-control and cross-sectional studies.

Since there are different methods for assessing adherence and self-care, as a way to standardize the analysis with the best possible scientific evidence, the studies considered were those that presented an evaluation of the referred outcomes through questionnaires with validated psychometric assessments, with the possibility of generating a final score, as a way of comparing the studies found.

Due to the statistical tests performed for this metaanalysis, this research considered studies with only two intervention groups. Studies that did not have a clear methodology and did not answer the study question were excluded.

The search was carried out in the following databases: PubMed, Cumulative Index of Nursing and Allied Health (CINAHL), LILACS, Cochrane and Scopus. The search for articles began in September 2019, through the registration on the website of the Federated Academic Community (Comunidade Acadêmica Federada, CAPES CAFe). The controlled descriptors were obtained through the Health Sciences Descriptors (Descritores em Ciências da Saúde, DeCS), MeSH (Medical Subject Headings) terms and CINAHL headings, according to the specificity of each database.

The descriptors selected were the following: heart failure/insuficiência cardíaca, health education/educação em saúde, patient compliance/cooperação do paciente, self-care/autocuidado, which were used for all search in the databases identically, using the Boolean operator "and" in the searches.

To achieve better results, the search was divided into two moments, one with the "patient compliance" descriptor and the other with the "self-care" descriptor. This division occurred because, by inserting patient compliance or self-care, the search was nonspecific, that is, there were many studies that were not related to the study objective. In this sense, according to what is recommended by PRISMA, the search strategy carried out in the PubMed database follows below, for future repetition:

For the patient compliance descriptor: (("heart failure"[MeSH Terms] OR ("heart"[All Fields] AND "failure"[All Fields]) OR "heart failure"[All Fields]) AND ("health education"[MeSH Terms] OR ("health"[All Fields]
AND "education"[All Fields]) OR "health education"[All Fields])) AND ("patient compliance"[MeSH Terms] OR ("patient"[All Fields] AND "compliance"[All Fields]) OR "patient compliance"[All Fields]).

For the self-care descriptor: (("heart failure"[MeSH Terms] OR ("heart"[All Fields] AND "failure"[All Fields]) OR "heart failure"[All Fields]) AND ("health education"[MeSH Terms] OR ("health"[All Fields] AND "education"[All Fields]) OR "health education"[All Fields])) AND ("self-care"[MeSH Terms] OR ("self"[All Fields] AND "care"[All Fields]) OR "self-care"[All Fields])

The search in the databases was carried out by the main researcher, who subsequently forwarded the abstracts of the articles found to two reviewers, who carried out the assessment blindly. The articles were assessed regarding titles and abstracts, where the eligibility criteria were applied; a third reviewer, who is trained by the JBI, assessed the possible divergences that occurred in the selection of abstracts for the final decision on whether to include or exclude them.

The abstracts assessed returned to the main researcher, who then made all articles available in fulltext format to the reviewers, who methodologically and blindly assessed them again. For this, the instruments of the Joanna Briggs Institute were used. At the end of this process, the articles that reached $70 \%$ of utilization were selected $^{(23)}$. Possible disagreements or doubts about the methodological assessment of the articles were clarified by a third reviewer trained by the JBI.

To reduce the possible risk of bias in the selection of studies, refinement was performed independently by two evaluators looking for $100 \%$ agreement; in addition, the same rule was applied to the results of the selection of studies, and there should be no divergence in the number of studies selected in each database.

In addition, the reviewers received from the qualified reviewer of the JBI a theoretical and practical systematic review training with a two-hour workload per instrument, totaling eight hours. This instrument consists of questions that assess the methodological quality of each review study included in the SR according to the method used.

The quality of the methodological evidence of the studies and the strength of recommendation were analyzed according to the precepts of the GRADE (Grading of Recommendations, Assessment, Development and Evaluation) system. This assessment considered the study design, its execution, consistent results, evidence, limitations, and data scarcity, as well as the probability of bias. The GRADE system considers four levels of evidence. There is high ( $A$ ) evidence when other studies are unlikely to change the estimated confidence in the 
effect of the intervention. There is moderate (B) evidence when there is moderate confidence in the estimated effect. When confidence in the effect is limited, it is considered low (C) and, when any effect estimate is uncertain, there is a very low level $(D)^{(24)}$.

The data were organized in charts and tables for the synthesis of information from the journals, such as: title, author's name, year of publication, in addition to the sample size, outcome result (mean) and standard deviation (or variance) of the control and intervention groups.

The means, standard deviation and sample size of the study were calculated. To calculate the effect size, the difference of means was performed, divided by the combined standard deviation, multiplied by a correction factor. To calculate the weights in each study, the inverse variance method was applied ${ }^{(25)}$.

The Fixed Effect and Random Effect models were used to represent the data and estimate the overall effect of the study. The fixed effect is a form of modeling that treats the selected studies as unique, thus the degree of importance (or weight) for calculating the overall effect is different for each study. The weight size is influenced by the quality of the estimates presented by the study. Two factors are decisive for calculating the weight, the variability found and the sample size used(25).

The results of the meta-analysis were presented using the forest plot graph, where each study is shown with its respective effect size, 95\% confidence interval, the weights for each model (fixed and random) and the estimate of the overall effect of the study(25). In order to account for the effect size, the standardized mean difference was used for both scales. The results were obtained by using the meta package of the R software.

\section{Results}

The search resulted in 802 studies which, after applying the eligibility criteria, derived in 19 studies: 15 with self-care outcome, and five (5) with adherence outcome. The study inclusion process is described in Figure 1.

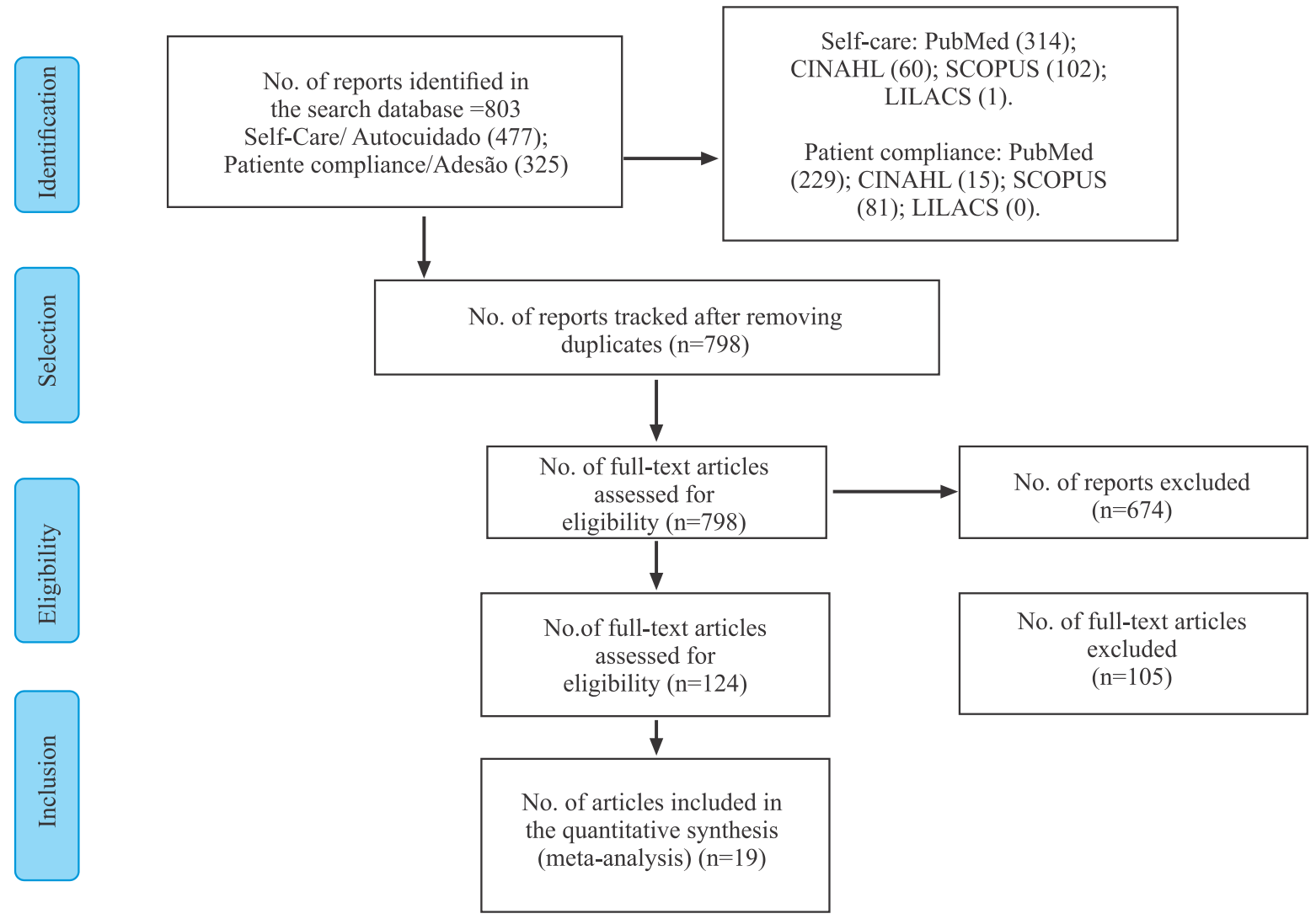

*No. of full-text articles excluded: The outcome is not self-care or patient compliance (41); Study protocol (6); The population does not have HF (6); Methodological study (8); Descritive / Qualitative study (7); Full text not available (5); Repetitions (5); Time cut <2012 (1): Metodological quality < 6 (2); More than one intervention group (5); Different assessment of validated questionnaires (8); Non-codable results (11).

Figure 1 - PRISMA flow diagram of selection of the studies. Niterói, RJ, Brazil, 2019 
Figure 2 briefly presents the respective studies included, with health education strategies presented to the patients randomized to the intervention group, with the various questionnaires validated to assess the self-care and adherence outcomes. The assessment scores in relation to the methodological quality of the JBI demonstrate that the articles obtained more than $70 \%$ of utilization.

The studies evaluated self-care in a total of 1,841 HF patients. For the outcome of adherence, a total of 974 individuals participated in the analyzed studies. These studies are mostly from the United States and China, from 2012 to 2018 , with the majority published in 2015. Of these, 11 studies used combined strategies.

It should be noted that, in the studies analyzed, the control group was treated with usual care, which was described in the studies as routine outpatient follow-up pursuant to institutional protocols.

\begin{tabular}{|c|c|c|c|c|c|c|c|c|c|}
\hline \multirow{2}{*}{$\begin{array}{l}\text { Studyl } \\
\text { Countryl } \\
\text { Year }\end{array}$} & \multirow{2}{*}{ Intervention/Professional } & \multirow{2}{*}{$\begin{array}{l}\text { Type of } \\
\text { study }\end{array}$} & \multicolumn{2}{|c|}{$\begin{array}{l}\text { Self-care } \\
\text { Scales }\end{array}$} & \multicolumn{4}{|c|}{ Adherence Scale } & \multirow{2}{*}{$\begin{array}{l}\text { JBI } \\
\text { score } \\
* *\end{array}$} \\
\hline & & & EHFSCBC* & $\mathrm{SCHFI}^{\dagger}$ & MARC ${ }^{\ddagger}$ & MMAC $\$$ & $\begin{array}{l}\text { MOSSAS- } \\
\text { 3HF\| }\end{array}$ & QA-26" & \\
\hline $\begin{array}{l}\text { Study } 1^{(26)} \\
\text { USA, } 2012\end{array}$ & Cognitive training. Nurse & $\mathrm{RCT}^{+t}$ & & $x$ & & & & & 12 \\
\hline $\begin{array}{l}\text { Study } 2^{(27)} \\
\text { Netherlands, } \\
2013\end{array}$ & $\begin{array}{l}\text { Nursing consultation + } \\
\text { Telemonitoring. Nurse }\end{array}$ & $\mathrm{RCT}^{\mathrm{tt}}$ & $x$ & & & & & & 12 \\
\hline $\begin{array}{l}\text { Study } 3^{(28)} \\
\text { USA, } 2017\end{array}$ & $\begin{array}{l}\text { Education for self-care/ } \\
\text { cultural adaptations }+ \\
\text { Phone consultation. Nurse }\end{array}$ & $\mathrm{RCT}^{+\dagger}$ & & $x$ & & & & & 12 \\
\hline $\begin{array}{l}\text { Study } 4^{(29)} \\
\text { USA, } 2015\end{array}$ & $\begin{array}{l}\text { Home Visit + Phone } \\
\text { consultation by } \\
\text { motivational interview. } \\
\text { Nurse }\end{array}$ & $\mathrm{RCT}^{++}$ & & $x$ & & & & & 12 \\
\hline $\begin{array}{l}\text { Study } 5^{(30)} \\
\text { China, } 2015\end{array}$ & Transitional care. Nurse & RCTtt & & $x$ & & & & & 11 \\
\hline $\begin{array}{l}\text { Study } 6^{(31)} \\
\text { Australia, } 2015\end{array}$ & $\begin{array}{l}\text { Electronic resource/ } \\
\text { Cultural adaptation. } \\
\text { Indigenous researcher }\end{array}$ & $Q^{\ddagger \ddagger}$ & & $x$ & & & & & 07 \\
\hline $\begin{array}{l}\text { Study } 7^{(32)} \\
\text { USA, } 2014\end{array}$ & $\begin{array}{l}\text { Group guidance + Lifestyle } \\
\text { coaching. Health educator }\end{array}$ & $\mathrm{RCT}^{+\dagger}$ & & $x$ & & & & & 11 \\
\hline $\begin{array}{l}\text { Study } 8^{(33)} \\
\text { Iran, } 2013\end{array}$ & $\begin{array}{l}\text { Education for self-care } \\
\text { after discharge + Phone } \\
\text { consultation. Nurse }\end{array}$ & $\mathrm{RCT}^{+t}$ & & $x$ & & & & & 13 \\
\hline $\begin{array}{l}\text { Study } 9^{(34)} \\
\text { Iran, } 2017\end{array}$ & $\begin{array}{l}\text { Education for self-care } \\
\text { by Motivational Interview. } \\
\text { Nurse }\end{array}$ & $\mathrm{RCT}^{+\dagger}$ & & $x$ & & & & & 11 \\
\hline $\begin{array}{l}\text { Study } 10^{(35)} \\
\text { USA, } 2015\end{array}$ & $\begin{array}{l}\text { Cognitive Behavioral } \\
\text { Therapy }\end{array}$ & $\mathrm{RCT}^{+t}$ & & $x$ & & & & & 11 \\
\hline $\begin{array}{l}\text { Study } 11^{(36)} \\
\text { Korea, } 2018\end{array}$ & $\begin{array}{l}\text { Nursing consultation }+ \\
\text { Phone consultation. Nurse }\end{array}$ & $Q^{\ddagger \ddagger}$ & $x$ & & & & & & 09 \\
\hline $\begin{array}{l}\text { Study } 12^{(37)} \\
\text { Iran, } 2015\end{array}$ & $\begin{array}{l}\text { Support group for patients } \\
\text { and family members. } \\
\text { Nurse }\end{array}$ & $Q^{\ddagger \ddagger}$ & $x$ & & & & & & 12 \\
\hline $\begin{array}{l}\text { Study } 13^{(38)} \\
\text { Netherlands, } \\
2014\end{array}$ & $\begin{array}{l}\text { Telemonitoring system } \\
\text { (Health Buddy }(\text { ) + Usual } \\
\text { care. Nurse }\end{array}$ & $\mathrm{RCT}^{+\dagger}$ & $x$ & & & & & & 12 \\
\hline
\end{tabular}




\begin{tabular}{|c|c|c|c|c|c|c|c|c|c|}
\hline \multirow{2}{*}{$\begin{array}{l}\text { Studyl } \\
\text { Countryl } \\
\text { Year }\end{array}$} & \multirow{2}{*}{ Intervention/Professional } & \multirow{2}{*}{$\begin{array}{l}\text { Type of } \\
\text { study }\end{array}$} & \multicolumn{2}{|c|}{$\begin{array}{l}\text { Self-care } \\
\text { Scales }\end{array}$} & \multicolumn{4}{|c|}{ Adherence Scale } & \multirow{2}{*}{$\begin{array}{l}\text { JBI } \\
\text { score } \\
* *\end{array}$} \\
\hline & & & EHFSCBC* & $\mathrm{SCHFI}^{+}$ & MARC ${ }^{\ddagger}$ & MMAC\$ & $\begin{array}{l}\text { MOSSAS- } \\
\text { 3HF" }\end{array}$ & QA-26" & \\
\hline $\begin{array}{l}\text { Study } 14^{(39)} \\
\text { Brazil, } 2013\end{array}$ & $\begin{array}{l}\text { Home visit after hospital } \\
\text { discharge + Phone } \\
\text { consultation. Nurse }\end{array}$ & $\mathrm{RCT}^{+\dagger}$ & $x$ & & & & & $x$ & 12 \\
\hline $\begin{array}{l}\text { Study } 15^{(40)} \\
\text { USA, } 2015\end{array}$ & $\begin{array}{l}\text { Education for self-care } \\
+ \text { Phone consultation + } \\
\text { Usual care. Nurse }\end{array}$ & $\mathrm{RCT}^{+\dagger}$ & $x$ & & & & & & 13 \\
\hline $\begin{array}{l}\text { Study } 16^{(41)} \\
\text { Germany, } 2016\end{array}$ & $\begin{array}{l}\text { Self-managed educational } \\
\text { group. Multi-professional } \\
\text { team (physician, nurse, } \\
\text { psychologist, and } \\
\text { physiotherapist) }\end{array}$ & $\mathrm{RCT}^{+\dagger}$ & & & $x$ & & & & 11 \\
\hline $\begin{array}{l}\text { Study } 17^{(42)} \\
\text { China, } 2015\end{array}$ & $\begin{array}{l}\text { Health education booklet } \\
+ \text { Phone consultation. } \\
\text { Physician and nurses }\end{array}$ & $\mathrm{RCT}^{+\dagger}$ & & & & $x$ & & & 11 \\
\hline $\begin{array}{l}\text { Study } 18^{(43)} \\
\text { USA, } 2018\end{array}$ & $\begin{array}{l}\text { Guidance through } \\
\text { ultrasound of the inferior } \\
\text { vena cava. Nurse }\end{array}$ & $\mathrm{RCT}^{\mathrm{tt}}$ & & & & & $x$ & & 11 \\
\hline $\begin{array}{l}\text { Study } 19^{(44)} \\
\text { China, } 2014\end{array}$ & $\begin{array}{l}\text { Home visit + Phone } \\
\text { consultation. Nurse }\end{array}$ & $\mathrm{RCT}_{\mathrm{tt}}$ & & & & & & $x$ & 12 \\
\hline
\end{tabular}

*EHFSCBC = European Heart Failure Self-care Behaviour Scale; ${ }^{+}$SCHFI = Self-Care of Heart Failure Index; ${ }^{\ddagger}$ MARC = Medication Adherence Report Scale; ${ }^{5}$ MMAC = Morisky Medication Adherence Scale; "MOSSAS-3HF = Medical Outcomes Study Specific Adherence Scale modified for HF; ${ }^{\mathrm{Q} A-26}=26$-point adherence questionnaire; $* *$ JBI $=$ Joanna Briggs Institute; ${ }^{+\dagger} \mathrm{RCT}=$ Randomized Clinical Trial; ${ }^{\ddagger \neq} \mathrm{QE}=$ Quasi-experimental

Figure 2 - Articles included for meta-analysis. Niterói, RJ, Brazil, 2019

Table 1 shows the size of the global effect for the self-care and adherence outcomes, respectively, according to the fixed and random models. With respect to selfcare, the fixed effect was not significant; thus, the control and intervention groups produced similar results. The global effects obtained by applying the fixed and random effects models were 0.0063 and 0.6799 , respectively. The models did not have convergent results. The fixed-effect model showed a non-significant result ( $p$-value $=0.8986$ ), showing that there are no differences in the self-care scale between the groups. However, the random-effect model obtained a significant result ( $p$-value $=0.0091$ ) in favor of the effect in the experimental group. Therefore, on average, the self-care results in the experimental group were higher than in the control group.

Regarding the adherence outcome, the global effects obtained by applying the fixed and random effects models were 0.3841 and 0.7604 , respectively. The models had convergent results. Both models were significant (fixed p-value $<0.001$ and random p-value 0.048). Therefore, on average, the results of adherence in the experimental group were higher than in the control group.

Table 1 - Result of the global effect size for the self-care and adherence scale, by model. Niterói, RJ, Brazil, 2019

\begin{tabular}{|c|c|c|c|c|}
\hline Model & Estimate & $95 \%$ confidence interval & z-value & p-value \\
\hline \multicolumn{5}{|c|}{ Outcome: Self-care } \\
\hline Fixed & 0.0063 & $(-0.0903 ; 0.1028)$ & 0.13 & 0.8986 \\
\hline Random & 0.6799 & $(0.1690 ; 1.1907)$ & 2.61 & 0.0091 \\
\hline \multicolumn{5}{|c|}{ Outcome: Adherence } \\
\hline Fixed & 0.3841 & $(0.2533 ; 0.5147)$ & 5.76 & $<0.001$ \\
\hline Random & 0.7604 & $(0.0038 ; 1.5170)$ & 1.97 & 0.0489 \\
\hline
\end{tabular}


Figure 3 presents the results of the meta-analysis considering the self-care and adherence outcomes, respectively. It was verified that, for self-care, studies No. 6 and No. 12 were those that came closest to the results in favor of the experimental group (intervention) ${ }^{(31,37)}$.

For the adherence outcome, the results were statistically significant in favor of the experimental group due to the fixed effect. Despite the small number of studies, the weights are distributed in an almost similar way among the papers.
The interventions implemented in these studies were, for the most part, two combined strategies: home visit (HV) + Phone consultation (PC) or PC with application of an educational leaflet ${ }^{(39-40,42,44)}$. There were also two individual strategies (personalized guidance based on the inferior vena cava ultrasound examination and educational group) $)^{(41,43)}$. Two studies (No. 14 and No. 19) that used $\mathrm{HV}+\mathrm{PC}$ were the ones that came closest to the result in favor of the experimental group for the adherence outcome ${ }^{(39,44)}$.

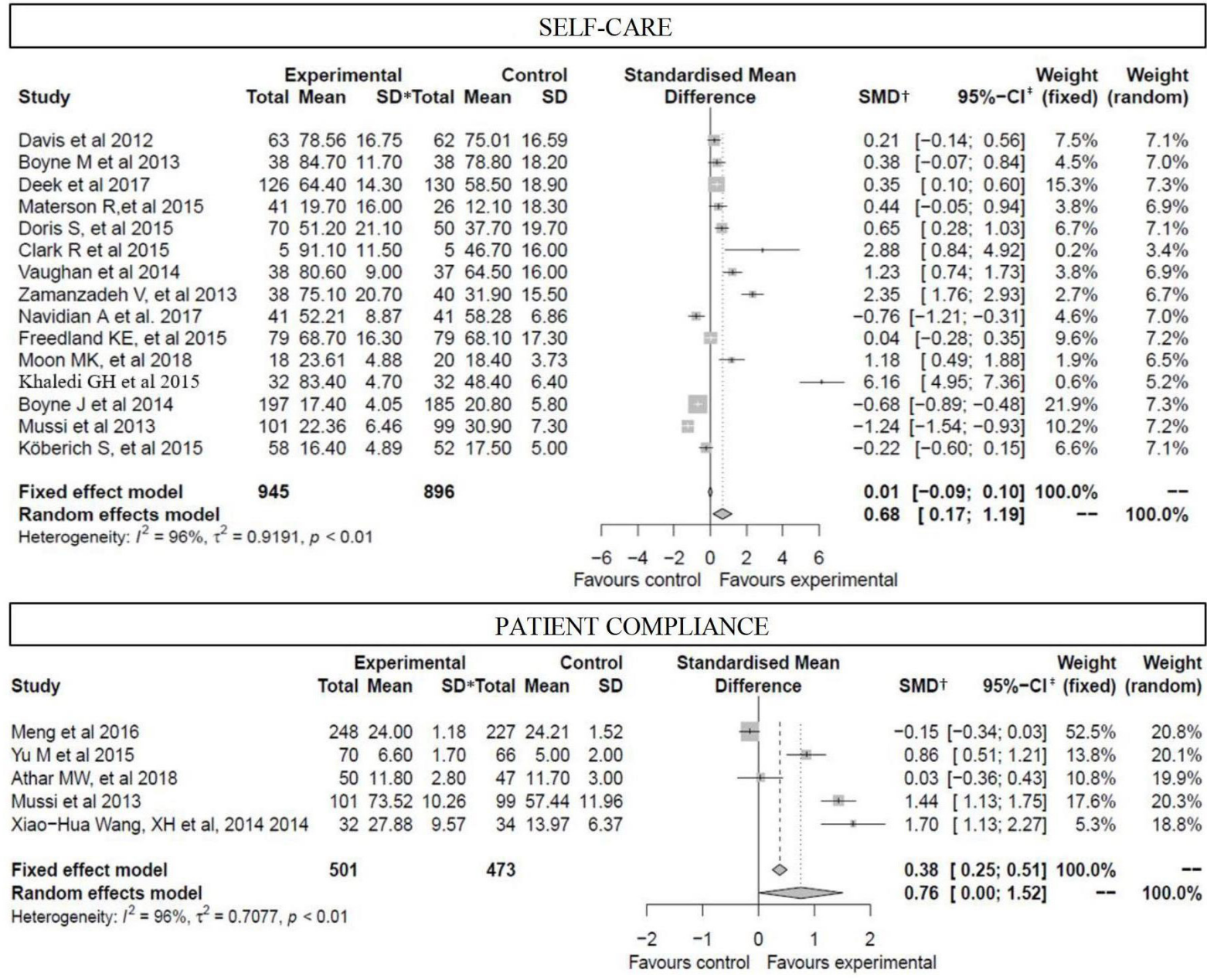

* $\mathrm{SD}=$ Standard Deviation/Desvio Padrão; ${ }^{\dagger} \mathrm{SMD}=$ Standarized Mean Differences/Diferença de Médias; ${ }^{\ddagger} 95 \%$-CI=95\% Confidence Interval/Intervalo de Confiança de 95\%.

Figure 3 - Result of applying the meta-analysis for the self-care and adherence outcomes, considering both fixed- and random-effect models. Niterói, RJ, Brazil, 2019

In Figure 4, the quality of evidence of the results assessed by the GRADE system was considered low for both outcomes, which suggests that confidence in the effect is limited. The risk of bias, inconsistency and imprecision were the main factors that determined the low quality of evidence in the studies assessed.

\begin{tabular}{|c|c|c|c|c|c|c|c|c|}
\hline $\begin{array}{l}\text { No. of the } \\
\text { study }\end{array}$ & Study design & Risk of bias* & Inconsistency ${ }^{\dagger}$ & $\begin{array}{c}\text { Uncertainty if } \\
\text { the evidence is } \\
\text { direct }\end{array}$ & Imprecision $\ddagger$ & $\begin{array}{l}\text { Publication } \\
\text { bias }\end{array}$ & Quality & Importance \\
\hline
\end{tabular}

Outcome: Self-care (Follow-up: 30 to 365 days, assessed by the following scales: EHFSCBC§ and SCHFI") 


\begin{tabular}{|c|c|c|c|c|c|c|c|c|}
\hline $\begin{array}{l}\text { No. of the } \\
\text { study }\end{array}$ & Study design & Risk of bias* & Inconsistency $^{\dagger}$ & $\begin{array}{l}\text { Uncertainty if } \\
\text { the evidence is } \\
\text { direct }\end{array}$ & Imprecision ${ }^{\ddagger}$ & $\begin{array}{l}\text { Publication } \\
\text { bias }\end{array}$ & Quality & Importance \\
\hline
\end{tabular}

Outcome: Adherence (Follow-up: 30 to 180 days, assessed by the following scales: MARC币, MMAC**, MOSSAS-3HF"† and QA-26 ${ }^{\ddagger \pm}$ )

Randomized

Clinical Trial

Not important

Important

Not important

Important

No

Low

Important

${ }^{*}$ Risk of bias $=\mathrm{A}$ quasi-experimental study with no allocation between control/intervention; ${ }^{\dagger}$ Inconsistency $=96 \%$ heterogeneity; ${ }^{\ddagger}$ Imprecision $=$ There are initial studies and with a small number of events; ${ }^{5}$ EHFSCBC = European Heart Failure Self-care Behaviour Scale; "ISCHFI = Self-Care of Heart Failure Index; "MARC $=$ Medication Adherence Report Scale; $* *$ MMAC $=$ Morisky Medication Adherence Scale; ${ }^{++}$MOSSAS-3HF $=$Medical Outcomes Study Specific Adherence Scale modified for HF; ${ }^{\neq \neq} \mathrm{QA}-26=26$-point adherence questionnaire

Figure 4 - GRADE Assessment. Niterói, RJ, Brazil, 2019

\section{Discussion}

The meta-analysis demonstrated that there was an improvement in the outcome of adherence to the treatment in the patients from the experimental group, both in the fixed-effect and in the random-effect models. The self-care outcome did not differ between the experimental and control groups when assessing the fixed model.

The interventions presented in the studies with effect on adherence to the treatment were predominantly combined strategies between HV+PC or PC with application of educational material. The individual strategies were the educational group in HF and health guidance based on the ultrasound of the inferior vena cava. From these studies, it was evidenced that those who used $\mathrm{HV}+\mathrm{PC}$ were the ones that had better significant results in favor of the experimental group ${ }^{(39,44)}$.

Corroborating this finding, in an experimental study with 201 patients, telephone follow-up took place seven and 30 days after discharge. There was an improvement in the outcome of medication and non-medication adherence after 90 days in the intervention group in relation to the control group $(p<0.001)^{(45)}$.

In a before-and-after experimental study conducted with patients hospitalized due to decompensated HF, in two reference institutions in Rio Grande do Sul, the intervention consisted of three home visits after hospital discharge, with an interval of 45 days. The outcome of adherence to the treatment was assessed using a validated questionnaire, in the first and third HVs. 32 patients were included, with a mean age of $65 \pm 16$ years old. The adherence scores were $16 \pm 2.6$ vs. $20.4 \pm 2.7$ on the first and third visits $(p=0.001)$. After the intervention, an increase in the score of adherence to the treatment of the patients with HF was evidenced, highlighting the improvement in questions related to daily weight verification and restriction of water intake ${ }^{(46)}$.

Personalized medicine is a current and extremely relevant approach, since it considers the particularities of each patient ${ }^{(47)}$. One of the studies included in this review used ultrasound images (USG) as an education strategy for patients with decompensated acute heart failure, relating the ultrasound image of their inferior vena cava (IVC) with its liquid state (congestion) ${ }^{(43)}$. Although this study did not show positive effects, another showed that an intervention that included educational materials based on images reduced hospitalization or death for a period of 12 months $^{(48)}$.

It has been shown that the educational group is a beneficial strategy in adherence to the treatment. A randomized clinical trial conducted in Brazil tested the effect of the guidance group on adherence to the treatment and self-care in patients with heart failure, showing an improvement from $13.9 \pm 3.6$ to $14.8 \pm 2.3$, from the initial to the final scores ${ }^{(14)}$. The authors concluded that, even with little difference in the initial and final scores, the adoption of an educational program is an important strategy in the health sector, especially in patients with chronic diseases ${ }^{(14)}$; however, it cannot guarantee a change in behavior because the relationship between what people know and adopt as a life habit is a tenuous and individual thing, which can be affected by several variables.

With regard to self-care, the fixed effect was not significant; thus, the control and experimental groups produced similar results. It is observed that three papers concentrate almost $40 \%$ of the global fixed effect, since they are studies with a good sample size and little variability found(38-40). Therefore, in the fixed-effect model, the papers differ in the degree of importance. Thus, it is not possible to state that the experimental effect produces differentiated results compared to the control group only when considering the random effect, in which the studies are treated as a sample of studies on the theme.

A systematic review identified 14 instruments for measuring self-care in patients with $\mathrm{HF}$ and two of them had undergone rigorous psychometric tests: European Heart Failure Self-Care Behaviour Scale (EHFScBS) and Self-Care of Heart Failure Index $(\mathrm{SCHFI})^{(49)}$. Other instruments are discussed in the literature, such as the Self-Care Behaviors Questionnaire (SCBQ) ${ }^{(50)}$ and the Test 
of Functional Health Literacy in Adults (S-TOFHLA), which assesses the level of health literacy, with psychometric validation for Brazil(51-52).

Although the fixed effect did not show differences between the experimental and control groups, the studies that individually came closest to the result in favor of the experimental group were related to the electronic resource ${ }^{(31)}$ and to the support group for patients and family members ${ }^{(37)}$.

The complexity of self-care in $\mathrm{HF}$ can pose threats to the proposal and adherence to treatments, especially in patients with low health literacy. This, in turn, is associated with the inability to process, understand and put into practice information about the disease, resulting in difficulties to understand and follow the guidelines for the proposed treatment, resulting in greater morbidity and mortality ${ }^{(53-54)}$. Recent studies have already associated low HF literacy with a deficit in knowledge of the disease, low self-care, readmissions and mortality ${ }^{(54-55)}$.

Socioeconomic, demographic and educational factors are determining factors in low health literacy. Patients with these conditions generally have difficulty processing information about the treatment of the disease, such as reading notes and labels on medications, and understanding verbal information from their health professionals and educational materials(16).

Patients with HF receive a range of health information and are often approached as passive recipients by health professionals, with little interaction between them. On the other hand, responsibility for self-care is often required. Therefore, it is of utmost importance to recognize the factors that interfere in the patient's understanding and participation in the management of the disease and treatment, so that they are analyzed in view of the implementation of strategies in order that the interventions occur more effectively and satisfactorily.

The national and international HF Guidelines indicate $\mathrm{HF}$ treatment programs as Class I, level of evidence " $\mathrm{A}$ " for improving adherence, self-care and quality of life, as well as reducing hospitalizations, mortality and hospital costs. The main component of this program is its multiprofessional constitution, focused on the education of patients and caregivers, whether on an outpatient or inpatient level, when planning discharge, using strategies such as face-to-face consultations, delivery of educational materials, telemonitoring and follow-up ${ }^{(1,20)}$.

Although the quality of the evidence of the results assessed by the GRADE system was considered low, this meta-analysis showed that combined educational strategies applied in patients with HF improved the compliance of patients with HF. Among them, the home visit together with phone consultation $(\mathrm{HV}+\mathrm{PC})$ is highlighted.

From the perspective of the work of nurses who handle HF patients, whether in HF outpatient clinics or during hospitalization, telephone consultation is considered a low-cost, easy-to-apply and quick-access strategy for patients. Home visits have the advantages of evaluating in loco and in real time the current situation of the patient, with the possibility of immediate interventions. The main disadvantage is the difficulty in accessing homes in at-risk crowded areas, both due to local violence and climatic conditions (landslides, flooding) and to the dependence on transportation for the health team.

In 2019, the American guideline for hospitalized patients with $\mathrm{HF}$ recommended that the PC should be performed with the patient and/or caregiver between 48 and 72 hours after discharge in order to check for signs of congestion, adherence to the treatment, clarification of doubts not discussed during hospitalization, and adequate access to prescription drugs ${ }^{(56)}$. The HV must be performed as soon as possible after discharge to reassess the clinical status and risk factors for readmission ${ }^{(56)}$.

Therefore, considering the findings of this study, the researchers recommend, as a priority, for better adherence to the treatment of HF patients, the adoption of combined $\mathrm{HV}+\mathrm{PC}$ strategies.

The reality of the HF patients treated by the Unified Health System (Sistema Único de Saúde, SUS) denotes characteristics of high vulnerability for recurrent hospitalizations ${ }^{(57)}$. Considering this aspect, telephone consultations combined with home visits, implemented in family health modules and specialized clinics, promote the following benefits: reduced intervals between faceto-face consultations; increased bond and trust between patients, family members and health professionals; situational diagnosis of the patient and family and prevention of hospitalizations due to HF decompensation for preventable causes, decreasing hospitalization costs by the SUS(58).

It is suggested that public institutions of basic/ specialized care add the HV+PC to their respective local care flows in referral and counter-referral systems in the access to patients with HF treated by the SUS.

In this meta-analysis, the method of assessing adherence occurred by applying validated questionnaires as a way to standardize the analysis. However, this outcome can be assessed in several ways, such as the number of medications taken per patient per week/ month, the measurement of serum biomarkers, and clinical examination. Given the diversity of estimates of this outcome, the results in this study must be analyzed with caution. 
Like the self-care outcome, the studies that measured adherence involved very different samples. In addition, the non-conformity of studies regarding the presentation of results with measures of mean and standard deviation or median made it impossible to include other studies that could have been contemplated in the meta-analysis, which is a limitation of this study.

This study highlights the limitations in conducting the meta-analysis related to the different ways of measuring self-care adherence today, as well as the high sample variability of the included studies. The methodology used in the statistical tests allowed for the analysis of studies with only two intervention groups. Further analyses are necessary to better estimate strategies that effectively impact on self-care in patients with HF.

\section{Conclusion}

Educational interventions improved the outcome of adherence, but not that of self-care in patients with HF. More detailed analyses are necessary, with the association of other clinical outcomes in order to consolidate the effect of the educational interventions on this population. It is suggested to include in future studies the outcome of health literacy to deepen the understanding and optimization of health education actions in HF.

\section{References}

1. Rohde LE, Montera MW, Bocchi EA, Clausell N, Albuquerque DC, Rassi $S$, et al. Diretriz Brasileira de Insuficiência Cardíaca Crônica e Aguda. Arq Bras Cardiol. [Internet]. 2018 [cited Dec 2, 2019];111(3):436-539. Available from: http://dx.doi.org/10.5935/abc.20180190 2. Stamp KD, Prasum M, Lee SL, Jaarsma T, Piano MR, Albert NM. Nursing research in heart failure care: a position statement of the American Association of Heart Failure Nurses (AAHFN). Heart Lung. [Internet]. 2018 [cited Dec 3, 2019];47(2):169-75. Available from: https:// doi.org/10.1016/j.hrtlng.2018.01.003

3. Ponikowski P, Anker SD, AlHabib KF, Cowie MR, Force $\mathrm{TL}, \mathrm{Hu} \mathrm{S}$, et al. Heart failure: preventing disease and death worldwide. ESC Heart Fail. [Internet]. 2014 [cited Dec 20, 2019];1(1):4-25. Available from: http://doi. org/10.1002/ehf2.12005

4. Cowie MR, Anker SD, Cleland JGF, Felker GM, Filippatos G, Jaarsma T, et al. Improving care for patients with acute heart failure: before, during and after hospitalization. ESC Heart Fail. [Internet]. 2014 [cited Dec 15, 2019];1:11045. Available from: https://doi.org/10.1002/ehf2.12021 5. Ministério da Saúde (BR). Departamento de Informática do SUS. Base de dados das Informações de Saúde:
Morbidade hospitalar do SUS por local de internação. [Internet]. 2019 [Acesso 25 dez 2019]. Disponível em: http://www2.datasus.gov.br/DATASUS/index.php?area=02. 6. Reuter AD, Rossi MB, Takao CL, Lima JL. Nonpharmacological interventions to improve quality of life in heart failure: an integrative review. Rev Bras Enferm. [Internet]. 2017 [cited Dec 30, 2019];70(1):198-209. Available from: http://dx.doi.org/10.1590/0034-71672016-0112

7. Alves PK, Constantini CO, Connstantini RC, Macedo $A C B$, Macedo RM. Pharmacological treatment adherence of patients with heart failure included in a supervised exercise program. ASSOBRAFIR Ciência. [Internet]. 2017 [cited Dec 2, 2019];8(1):23-30. Available from: http://www.uel.br/revistas/uel/index.php/rebrafis/article/ view/26284/21199

8. Qavam SM, Sahebi A, Shohani M, Balavandi F, Qavam $\mathrm{R}$, Tavan H. Investigating the Effect of Education on SelfCare among Chronic Heart Failure Patients Admitted to Shahid Mostafa Khomeini Hospital of Ilam. Glob J Health Sci. [Internet]. 2017 [cited Dec 2, 2019];9(5):79-84. Available from: http://dx.doi.org/10.5539/gjhs.v9n5p79 9. Yancy CW, Jessup M, Bozkurt B, Butler J, Casey DE, Drazner $\mathrm{MH}$, et al. 2013 ACCF/AHA guideline for the management of heart failure: executive summary: a report of the American College of Cardiology Foundation/ American Heart Association Task Force on practice guidelines. Circulation. J Am Coll Cardiol. [Internet]. 2013 [cited Dec 15, 2019];128(16):1810-52. Available from: https://doi.org/10.1016/j.jacc.2013.05.020

10. Riegel B, Lee CS, Dickson VV, Carlson B. An update on the self-care of heart failure index. J Cardiovasc Nurs. [Internet]. 2009 [cited Sep 15, 2019];24(6):485-97. Available from: 10.1097/JCN.0b013e3181b4baa0

11. Riegel B, Dickson VV, Lee CS, Daus M, Hill J, Irani E, et al. A mixed methods study of symptom perception in patients with chronic heart failure. Heart Lung. [Internet]. 2018 [cited Sep 15, 2019];47(1):1-8. Available from: https://doi.org/10.1016/j.hrtlng.2017.11.002

12. Rêgo MLM, Cabral DAR, Fontes EB. Cognitive Deficit in Heart Failure and the Benefits of Aerobic Physical Activity. Arq Bras Cardiol. [Internet]. 2018 [cited Dec 16, 2019];110(1):91-4. Available from: http://dx.doi. org/10.5935/abc. 20180002

13. Gordoreski EZ, Goyal P, Hummel SL, Krishnaswami A, Goodlin SJ, Hart L, et al. Domain Management Approach to Heart Failure in the Geriatric Patient. J Am Coll Cardiol. [Internet]. 2018 [cited Sep 16, 2019];71(17):192136. Available from: https://doi.org/10.1016/j. jacc. 2018.02.059

14. Arruda CS, Pereira JMV, Figueiredo LS, Scofano BS, Flores PVP, Cavalcanti ACD. Effect of an orientation 
group for patients with chronic heart failure: randomized controlled trial. Rev. Latino-Am. Enfermagem. [Internet]. 2017 [cited Sep 26, 2019];25:e2982. Available from: http://doi.org/10.1590/1518-8345.2167.2982

15. Alspach JG. Heart Failure and Low Health Literacy: Mitigating This Lethal Combination. Editorial. Crit Care Nurse. [Internet]. 2015 [cited Dec 19, 2019];35(5):104. Available from: https://doi.org/10.4037/ccn2015734 16. Cajita MI, Cajita TR, Han H. Health Literacy and Heart Failure: A Systematic Review. J Cardiovasc Nurs. [Internet]. 2016 [cited Dec 22, 2019];31(2):121-30. Available from: http://doi.org/10.1097/JCN.0000000000000229

17. Silva AF, Cavalcanti ACD, Malta M, Arruda CS, Gandin $T$, Fé $A$, et al. Treatment adherence in heart failure patients followed up by nurses in two specialized clinics. Rev. Latino-Am. Enfermagem. [Internet]. 2015 [cited Sep 15, 2019];23(5):888-94. Available from: http://doi. org/10.1590/0104-1169.0268.2628

18. Srisuk N, Cameron J, Ski CF, Thompson DR. Randomized controlled trial of family-based education for patients with heart failure and their carers. J Adv Nurs. [Internet]. 2017 [cited Sep 15, 2019];73(4):85770. Available from: https://doi.org/10.1111/jan.13192 19. Halmo R, Galuszkab J, Langovad K, Galuszkovac D. Self care in patients with chronic heart failure. Pilot study - self care includes problems. Biomed Pap Med Fac Univ Palacky Olomouc Czech Repub. [Internet]. 2015 [cited Sep 20, 2019];159(1):124-30. Available from: http:// dx.doi.org/10.5507/bp.2013.044

20. Ponikowski P, Voors AA, Anker SD, Bueno H, Cleland JG, Coats AJ, et al. 2016 ESC Guidelines for the diagnosis and treatment of acute and chronic heart failure: The Task Force for the diagnosis and treatment of acute and chronic heart failure of the European Society of Cardiology (ESC) Developed with the special contribution of the Heart Failure Association (HFA) of the ESC. Eur Heart J. [Internet]. 2016 [cited Sep 15, 2019];37(27):2129-200. Available from: https://doi.org/10.1093/eurheartj/ehw128 21. Galvão TF, Pansani TSA, Harrad D. Principais itens para relatar revisões sistemáticas e meta-análises: A recomendação PRISMA. Epidemiol Serv Saúde. [Internet]. 2015 [Acesso 18 dez 2019];24(2):335-45. Disponível em: https://doi.org/10.5123/S1679-49742015000200017 22. Santos CMC, Pimenta CAM, Nobre MRC. The PICO strategy for the research question construction and evidence search. Rev. Latino-Am. Enfermagem. [Internet]. 2007 [cited Dec 20, 2019];15(3):508-11. Available from: http://dx.doi.org/10.1590/S0104-11692007000300023 23. Tufanaru C, Munn Z, Aromataris E, Campbell J, Hopp L. Chapter 3: Systematic reviews of effectiveness. Joanna Briggs Institute Reviewer's Manual. [Internet]. 2017 [cited Dec 20, 2019]. Available from: https://wiki.joannabriggs.
org/display/MANUAL/Chapter+3\%3A+Systematic+revie ws+of+effectiveness

24. Ministério da Saúde (BR). Secretaria de Ciência, Tecnologia e Insumos Estratégicos. Departamento de Ciência e Tecnologia. Diretrizes metodológicas: Sistema GRADE - Manual de graduação da qualidade da evidência e força de recomendação para tomada de decisão em saúde. [Internet]. 2014 [cited Nov 25, 2019]. Available from: http://bvsms.saude.gov.br/bvs/publicacoes/ diretrizes_metodologicas_sistema_grade.pdf

25. Shorten A, Shorten B. What is meta-analysis? Evid Based Nurs. [Internet]. 2013 [cited Dec 30, 2019];16(1):3-4. Available from: http://doi.org/10.5123/ S1679-49742015000200017

26. Davis KK, Mintzer M, Himmelfarb CRD, Hayat M, Rotman S, Allen J. Targeted intervention improves knowledge but not self-care or readmissions in heart failure patients with mild cognitive impairment. Eur ] Heart Fail. [Internet]. 2012 [cited Dec 30, 2019];14(9):1041-9. Available from: https://doi. org/10.1093/eurjhf/hfs096

27. Boyde M, Song S, Peters R, Turner C, Thompson DR, Stewart S. Pilot testing of a self-care education intervention for patients with heart failure. Eur J Cardiovasc Nurs. [Internet]. 2013 [cited Dec 15, 2019];12(1):39-46. Available from: https://doi. org/10.1177/1474515111430881

28. Deek $H$, Chang $S$, Newton PJ, Noureddine S, Inglis $\mathrm{SC}$, Arab GA, et al. An evaluation of involving family caregivers in the self-care of heart failure patients on hospital readmission: Randomised controlled trial (the FAMILY study). Int J Nurs Stud. [Internet]. 2017 [cited Dec 3, 2019];75:101-11. Available from: https://doi. org/10.1177/1474515111430881

29. Masterson CR, Patey M, Lee CS, Kuan A, Jurgens C, Riegel $B$. Motivational interviewing to improve self-care for patients with chronic heart failure: MITI-HF randomized controlled trial. Patient Educ Couns. [Internet]. 2016 [cited Dec 15, 2019];99(2):256-64. Available from: https://doi.org/10.1016/j.pec.2015.08.031

30. Yu DS, Lee DT, Stewart S, Thompson DR, Choi KC, Yu CM. Cognitive Behavior Therapy for Depression and Self-Care in Heart Failure Patients: A Randomized Clinical Trial. J Am Geriatr Soc. [Internet]. 2015 [cited Dec 15, 2019];63(8):1583-93. Available from: 10.1001/ jamainternmed.2015.5220

31. Clark AM, Spaling M, Harkness K, Spiers J, Strachan $\mathrm{PH}$, Thompson DR, et al. Determinants of effective heart failure self-care: a systematic review of patients' and caregivers' perceptions. Heart. [Internet]. 2014 [cited Sep 15, 2019];100:716-21. Available from: http://dx.doi. org/10.1136/heartjnl-2013-304852 
32. Dickson VV, Melkus GD, Katz S, Levine-Wong A, Dillworth J, Cleland CM, et al. Building skill in heart failure self-care among community dwelling older adults: results of a pilot study. Patient Educ Couns. [Internet]. 2014 [cited Dec 15, 2019];96(2):188-96. Available from: https://doi.org/10.1016/j.pec.2014.04.018

33. Zamanzadeh $V$, Valizadeh $L$, Howard AF, Jamshidi F. A supportive-educational intervention for heart failure patients in Iran: the effect on self-care behaviours. Nurs Res Pract. [Internet]. 2013 [cited Dec 10, 2019];2013:01-7. Available from: http://dx.doi. org/10.1155/2013/492729

34. Navidian A, Mobaraki $H$, Shakiba M. The effect of education through motivational interviewing compared with conventional education on self-care behaviors in heart failure patients with depression. Patient Educ Couns. [Internet]. 2017 [cited Sep 10, 2019];100(8):1499504. Available from: https://doi.org/10.1016/j. pec.2017.02.023

35. Freedland KE, Carney RM, Rich MW, Steinmeyer BC, Rubin EH. Cognitive Behavior Therapy for Depression and Self-Care in Heart Failure Patients: a Randomized Clinical Trial. JAMA Intern Med. [Internet]. 2015 [cited Sep 10, 2019];175(11):1773-82. Available from: http:// doi.org/10.1001/jamainternmed.2015.5220

36. Moon MK, Yim J, Jeon MY. The effect of a telephonebased self-management program led by nurses on selfcare behavior, biological index for cardiac function and depression in ambulatory heart failure patients. Asian Nurs Res (Korean Soc Nurs Sci). [Internet]. 2018 [cited Sep 10, 2019];12(4):251-7. Available from: https://doi. org/10.1016/j.anr.2018.10.001

37. Khaledi GH, Mostafavi F, Eslami AA, Rooh Afza H, Mostafavi F, Akbar H. Evaluation of the effect of perceived social support on promoting self care behaviors of heart failure patients referred to the cardiovascular research center of Isfahan. Iran Red Crescent Med J. [Internet]. 2015 [cited Sep 15, 2019];17(6):e22525. Available from: http://doi.org/10.5812/ircmj.22525v2

38. Boyne JJ, Vrijhoef HJ, Spreeuwenberg M, De Weerd G, Kragten J, Gorgels AP. Effects of tailored telemonitoring on heart failure patients knowledge, self-care, self efficacy and adherence: a randomized controlled trial. Eur J Cardiovasc Nurs. [Internet]. 2014 [cited Oct 10, 2019];13(3):243-52. Available from: https://doi. org/10.1177/1474515113487464

39. Mussi CM, Ruschel K, Souza EN, Lopes ANM, Trojahn MM, Paraboni CC, et al. Home visit improves knowledge, self-care and adhesion in heart failure: Randomized Clinical Trial HELEN-I1 Rev. Latino-Am. Enfermagem. [Internet]. 2013 [cited Oct 15, 2019];21(Spec). Available from: http://dx.doi.org/10.1590/S0104-11692013000700004
40. Köberich S, Lohrmann C, Mittag O, Dassen T. Effects of a hospital-based education programme on selfcare behaviour, care dependency and quality of life in patients with heart failure - a randomized controlled trial. J Clin Nurs. [Internet]. 2015 [cited Oct 15, 2019];24(1112):1643-55. Available from: https://doi.org/10.1111/ jocn. 12766

41. Meng K, Musekamp G, Schuler M, Seekatz B, Glatz J, Karger G, et al. The impact of a self-management patient education program for patients with chronic heart failure undergoing inpatient cardiac rehabilitation. Patient Educ Couns. [Internet]. 2016 [cited Oct 25, 2019];99(7):1190-7. Available from: https://doi. org/10.1016/j.pec. 2016.02.010

42. Yu DS, Lee DT, Thompson DR, Woo J, Leung E. Assessing self-care behaviour of heart failure patients: cross-cultural adaptation of two heart failure selfcare instruments. Hong Kong Med J. [Internet]. 2010 [cited Oct 20, 2019];16(3):13-6. Available from: https://www. hkmj.org/system/files/hkm1006sp3p13.pdf

43. Athar MW, Record JD, Martire C, Hellmann DB, Ziegelstein RC. The effect of a personalized approach to patient education on heart failure self-management. J Pers Med. [Internet]. 2018 [cited Oct 15, 2019];8(4):01-10. Available from: https://doi.org/10.3390/jpm8040039

44. Wang XH, Qiu JB, Ju Y, Chen GC, Yang JH, Pang $\mathrm{JH}$, et al. Reduction of heart failure rehospitalization using a weight management education intervention. J Cardiovasc Nurs. [Internet]. 2014 [cited Oct 15, 2019];29(6):528-34. Available from: http://doi. org/10.1097/JCN.0000000000000092

45. Oscalices MIL, Okuno MFP, Lopes MCBT, Campanharo CRV, Batista REA. Discharge guidance and telephone follow-up in the therapeutic adherence of heart failure: randomized clinical trial. Rev. Latino-Am. Enfermagem. 2019;27:e3159. [cited Jan 15, 2020]; Available from: http://dx.doi.org/10.1590/1518-8345.2484.3159

46. Montovani VM, Ruchel KB, Souza EN, Mussi CM, Silva ERR. Treatment adherence in patients with heart failure receiving nurse-assisted home visits. Acta Paul Enferm. [Internet]. 2015 [cited Dec 10, 2019];28(1):417. Available from: http://dx.doi.org/10.1590/19820194201500008

47. Ziegelstein RC. Personomics: The Missing Link in the Evolution from Precision Medicine to Personalized Medicine. J Pers Med. [Internet]. 2017 [cited Dec 10, 2019];7(4):11. Available from: https://doi.org/10.3390/ jpm7040011

48. DeWalt DA, Malone RM, Bryant ME, Kosnar MC, Corr $K E$, Rothman RL, et al. A heart failure self-management program for patients of all literacy levels: a randomized, controlled trial. BMC Health Serv Res. [Internet]. 2006 
[cited Dec 3, 2019];6(30):1-10. Available from: http:// doi.org/10.1186/1472-6963-6-30

49. Cameron J, Worrall-Carter L, Driscoll A, Stewart $S$. Measuring self-care in chronic heart failure: review of the psychometric properties of clinical instruments. J Cardiovasc Nurs. [Internet]. 2009 [cited Dec 5, 2019];24(6):10-22. Available from: 10.1097/ JCN.0b013e3181b5660f.

50. Wagenaar KP, Broekhuizen BDL, Rutten FH, Strömberg $A$, van Stel HF, Hoes AW, et al. Interpretability of the European Heart Failure Self-care Behaviour scale. Patient Prefer Adher. 2017;11:1841-9. doi: 10.2147/PPA.S144915 51. Parker RM, Baker DW, Williams MV, Nurss JR. The Test of Functional Health Literacy in Adults: A New Instrument for Measuring Patients' Literacy Skills. J Gen Intern Med. [Internet]. 1995 [cited Dec 2, 2019];10(10):53741. Available from: https://www.ncbi.nlm.nih.gov/ pubmed/8576769

52. Maragno CA, Daros, MSS, Moraes CG, Rebelo MVD, Guimarães AMM, Pizzol TSD. Test of health Literacy for Portuguese-speaking Adults. [Internet]. 2019 [cited Dec 15, 2019];22:e190025. Available from: http://dx.doi. org/10.1590/1980-549720190025

53. Fabbri M, Yost K, Rutten LJF, Manemann SM, Boyd $C M$, Jensen $D$, et al. Health Literacy and Outcomes in Patients With Heart Failure: A Prospective Community Study. Mayo Clin Proc. [Internet]. 2018 [cited Dec 10, 2019];93(1):9-15. Available from: https://doi. org/10.1016/j.mayocp.2017.09.018

54. Peterson PN, Shetterly SM, Clarke CL, Bekelman DB, Chan PS, Allen LA, et al. Health Literacy and Outcomes Among Patients With Heart Failure. JAMA. [Internet]. 2011 [cited Dec 15, 2019];305(16):1695-701. Available from: http://doi.org/10.1001/jama.2011.512

55. León-González R, García-Esquinas E, Paredes-Galán E, Ferrero-Martínez AI, González-Guerrero JL, HornillosCalvo $M$, et al. Health literacy and health outcomes in very old patients with heart failure. Rev Esp Cardiol. [Internet]. 2018 [cited Dec 10, 2019];71(3):178-84. Available from: http://doi.org/10.1016/j.rec.2017.06.010

56. Hollenberg SM, Stevenson, CLW. 2019 ACC Expert Consensus Decision Pathway on Risk Assessment, Management, and Clinical Trajectory of Patients
Hospitalized With Heart Failure. J Am Coll Cardiol. [Internet]. 2019 [cited Dec 10, 2019];74(15):19662011. Available from: https://doi.org/10.1016/j. jacc.2019.08.001

57. Mesquita ET, Jorge AJL, Rabelo LM, Souza CV. Understanding Hospitalization in Patients with Heart Failure. Int ] Cardiovasc Sci. [Internet]. 2017 [cited Jun 15, 2020];30(1):81-90. Available from: https://doi. org/10.5935/2359-4802.20160060

58. Figueiredo LS, Flores PVP, Dias BF, Cruz DCS, Jardim $\mathrm{PP}$, Borges AS, et al. Remote monitoring of patients with chronic heart failure in times of social distance - COVID-19 in the light of the "Primary Nursing" model. Res Soc Dev. [Internet]. 2020 [cited Jun 15, 2020];9(7):1-17. Avaliable from: http://dx.doi.org/10.33448/rsd-v9i7.3909

\section{Authors' contribution:}

Study concept and design: Juliana de Melo Vellozo Pereira Tinoco, Lyvia da Silva Figueiredo, Paula Vanessa Peclat Flores, Evandro Tinoco Mesquita, Ana Carla Dantas Cavalcanti. Obtaining data: Juliana de Melo Vellozo Pereira Tinoco, Lyvia da Silva Figueiredo, Paula Vanessa Peclat Flores, Bruna Lins Rocha de Padua. Data analysis and interpretation: Juliana de Melo Vellozo Pereira Tinoco, Bruna Lins Rocha de Padua, Evandro Tinoco Mesquita, Ana Carla Dantas Cavalcanti. Drafting the manuscript: Juliana de Melo Vellozo Pereira Tinoco, Lyvia da Silva Figueiredo, Paula Vanessa Peclat Flores, Bruna Lins Rocha de Padua, Evandro Tinoco Mesquita, Ana Carla Dantas Cavalcanti. Critical review of the manuscript as to its relevant intellectual content: Juliana de Melo Vellozo Pereira Tinoco, Lyvia da Silva Figueiredo, Paula Vanessa Peclat Flores, Bruna Lins Rocha de Padua, Evandro Tinoco Mesquita, Ana Carla Dantas Cavalcanti.

All authors approved the final version of the text. Conflict of interest: the authors have declared that there is no conflict of interest. Creative Commons (CC BY). 